\title{
Effect of Chronic Caffeine Intake on Myocardial Function during Early Growth
}

\author{
THOMAS E. TEMPLES, DOLLY J. GEOFFRAY, TETSUO NAKAMOTO, ARTHUR D. HARTMAN,
} AND HARVEY I. MILLER

Louisiana State University Medical Center, Department of Physiology, New Orleans, Louisiana 70112

\begin{abstract}
The purpose of these studies was to evaluate the effects of chronic caffeine ingestion on the myocardium during fetal and neonatal growth and development. The isolated perfused working heart preparation was used to evaluate cardiac function. During gestation and lactation, one group of dams consumed a caffeine supplemented diet $(10 \mathrm{mg} / \mathrm{kg} / \mathrm{day})$. Their offspring were sacrificed and the hearts analyzed 50 days after birth. We found that the intake of caffeine by the dams resulted in significant increases in the offspring's coronary flow, peak systolic pressure, and myocardial work. A second group of dams ingested a diet containing caffeine $(10 \mathrm{mg} / \mathrm{kg} / \mathrm{day})$ during lactation only. Their pups continued to consume the caffeine diet until 50 days. Pup hearts exhibited significant reductions in cardiac output, stroke volume, pressure development, myocardial work, and external efficiency when compared to controls. Caffeine did not affect (a) body or heart weight or (b) adipose size or number in these experiments. Thus, continued caffeine consumption following birth may alter cardiac performance of the offspring. ( $P e$ diatr Res 21: 391-395, 1987)
\end{abstract}

\section{Abbreviations}

$\dot{Q}$, cardiac output

PSP, peak systolic pressure

HR, heart rate

$\mathrm{SV}$, stroke volume

CF, coronary flow

Caffeine is extensively used $(1,2)$ and therefore much concern has arisen concerning its potential for developmental toxicity. Caffeine is known to affect the central nervous system, cardiac muscle, cardiac output (2-4), blood pressure, heart rate (1), catecholamine release, and renin activity $(2,5,6)$. Although the exact mechanisms of caffeine's cardiovascular effects are still controversial (7), the reports imply that the organism rapidly develops a tolerance to caffeine's acute actions and that the acute effects do not persist $(5,8)$.

Presently, insufficient information is available regarding chronic caffeine administration during early growth and development. Researchers have reported that caffeine and its metabolites readily cross the placenta and distribute evenly in fetal

Received June 25, 1986; accepted November 26, 1986.

Address correspondence to Dr. Thomas E. Temples, University of Denver, Department of Sport Sciences and Physical Education, 2000 S. Gaylord, Denver, CO 80208

Address reprint requests to Dr. Harvey I. Miller, Louisiana State University Medical Center, Department of Physiology, 1901 Perdido Street, New Orleans, LA 70112.

Supported by a National Institutes of Health Cardiovascular Training Grant HL-07098. tissue (9-12). During pregnancy, all the caffeine may not be metabolized $(13,14)$ possibly causing an accumulation in maternal and fetal tissues. Caffeine has also been found in mother's milk $(15,16)$; thus, caffeine is available to the suckling infant. In addition, caffeine is known to activate the sympathetic nervous system, evaluate plasma free fatty acids (17-20), and decrease adipocyte size (21).

The purposes of the present study were: (a) to determine whether caffeine ingestion by dams during fetal development and lactation had any long-term effect on the offspring's cardiac performance 50 days after birth, (b) to ascertain whether caffeine intake by the offspring during nursing and after weaning resulted in cardiac dysfunction in 50-day-old rats, and (c) to evaluate whether chronic caffeine consumption for 50 days during lactation and postweaning affected adipocyte size and number.

\section{METHODS}

Effect of caffeine intake during gestation and lactation. Timed pregnant (known date of conception) Sprague-Dawley rats (Holtzman Co., Madison, WI) were fed Purina Laboratory Chow at our animal facility. On day 13 of pregnancy (sperm positive as day 1), randomly selected dams in the control group were fed a $20 \%$ protein diet (22). These control dams were fed ad libitum. On delivery, several litters were combined if the delivery time was within an 8-h range. Randomly selected pups were then assigned to each dam and the dams consumed the same diet during lactation. In conducting this research, the investigators adhered to "Guiding Principles in the Care and Use of Animals" as described by the Council of The American Physiological Society.

During pregnancy, dams in the experimental group were pairfed to controls the same diet supplemented with caffeine $(10 \mathrm{mg} /$ $\mathrm{kg}$ /day). On delivery, pups were randomly assigned to dams and the dams were pair-fed the caffeine supplemented diet during lactation.

After the pups were weaned at day 22, only male animals were selected. Pups from both groups were then pair-fed the control diet without caffeine until sacrificed 50 days after birth. Caffeine quantities in the diet were adjusted for increased body weight and food intake. All rats were housed individually and water was provided ad libitum.

The fasted animals (12-h postabsorptive) were injected intraperitoneally with $500 \mathrm{U}$ heparin and anesthetized with sodium pentobarbital $(50 \mathrm{mg} / \mathrm{kg}$ body weight). The hearts were excised, placed in cold saline, and then the cardiovascular performance of the caffeine-fed and control groups were examined by using the isolated working heart preparation as described previously $(23,24)$. Retrograde perfusion of the coronaries was initiated using an oxygenated, nonrecirculating Krebs-Henseleit bicarbonate buffer $(\mathrm{pH} 7.40)$ with glucose $(5.5 \mathrm{mM})$. The buffer was equilibrated with $95 \% \mathrm{O}_{2}-5 \% \mathrm{CO}_{2}$ at $37^{\circ} \mathrm{C}$. Final salt concentrations in the perfusion medium were (in $\mathrm{mM}$ ): $\mathrm{NaCl} 118, \mathrm{KCl}$ 
4.7, $\mathrm{MgSO}_{4}, 2.4, \mathrm{KH}_{2} \mathrm{PO}_{4}$ 1.2, $\mathrm{NaHCO}_{3}$ 25, NaEDTA 1.0, and $\mathrm{CaCl}_{2} 2$ 2.8. Perfusion was continued for approximately $10 \mathrm{~min}$ while the left atrial appendage and the pulmonary artery were cannulated. After the cannulation procedures were completed, antegrade perfusion via the left atrial cannula was begun.

For the first $10 \mathrm{~min}$ of antegrade perfusion, the heart was perfused at a preload (left atrial filling pressure) of $15 \mathrm{~cm} \mathrm{H}_{2} \mathrm{O}$. Hearts were paced (Grass Stimulator, model SD9) at 235-240 beats per min and the workload varied by altering the preload pressure. The afterload was maintained at $70 \mathrm{~cm} \mathrm{H}_{2} \mathrm{O}$. After stabilization, the hearts were perfused at left atrial filling pressures of $10,15,20,25,30$, and then back to $15 \mathrm{~cm} \mathrm{H}_{2} \mathrm{O}$. Each left atrial filling pressure was maintained for $5 \mathrm{~min}$ before measurements were recorded. The buffer $(1000 \mathrm{ml})$ was recirculated throughout each experiment using new buffer for each heart.

Effect of caffeine intake during lactation and postweaning. Timed pregnant Sprague-Dawley rats were fed Purina Laboratory Chow until delivery. At birth, several litters were combined if the time of delivery was within an 8-h range. Eight randomly selected pups were assigned to each dam. Control dams were then fed a $20 \%$ protein diet (22) ad libitum. Dams in the experimental group were pair-fed to the control group with the $20 \%$ protein diet supplemented with caffeine $(10 \mathrm{mg} / \mathrm{kg} / \mathrm{day})$. When the pups were weaned at day 22 , only males were selected. The weaned pups continued to receive either the control or experimental (caffeine) diet until sacrificed at day 50. Caffeine amounts in the diet were adjusted for increased body weight and food intake. All rats were housed individually and water was provided ad libitum. Similar experimental procedures were conducted as described above with regard to cardiac performance and the isolated working heart preparation. In addition, both the entire epididymal and perirenal fat depots were removed, rinsed in saline, and weighed. Adipocytes were isolated and both cell size and number per fat pad were determined as previously described (25).
Calculations and statistics. At each preload, coronary and aortic flow were measured. All flow related measurements were normalized to dry heart weight. Oxygen in the left atrial buffer reservoir and the coronary effluent were measured employing an oxygen probe and monitor (Yellow Springs Instruments, models 5331 and 53, respectively). Oxygen consumption and external efficiency were calculated $(24,26)$ with oxygen consumption expressed as mmoles oxygen consumed per hour per gram dry heart weight and external efficiency as a percentage. An estimate of myocardial work (double product) was calculated as $\dot{Q}$ times PSP.

Data are expressed as mean \pm SEM. A two-way analysis of variance with repeated measures design was used to evaluate the differences between groups and preload pressures. A NewmanKeuls multiple range test was used to determine significant differences between means. When appropriate, $t$ tests were used to test mean differences. Correlations were used to determine relationships between variables while regression analysis was used to evaluate oxygen consumption and coronary flow in relation to estimated myocardial work. Statistical differences were considered significant at $p<0.05(27,28)$.

\section{RESULTS}

Effect of caffeine intake during gestation and lactation. No significant differences in body weight were observed between the control and caffeine-fed groups at 50 days postbirth. Although wet heart weight for the caffeine-fed animals was significantly less than those of controls $(1.198 \pm 0.069$ and $1.353 \pm 0.019 \mathrm{mg}$, respectively), there was no significant difference in dry heart weight between the two groups.

In both groups, in vitro $\mathrm{Q}$ increased significantly with preload pressure (Table 1); however, the differences between groups were not significant. Similarly, HR and SV were not significantly different between controls and caffeine-fed rats. CF was signifi-

Table 1. Effects of chronic caffeine intake during gestation and lactation on cardiac performance (mean $\pm S E M)$

\begin{tabular}{|c|c|c|c|c|c|}
\hline \multirow[b]{2}{*}{ Variable } & \multicolumn{5}{|c|}{ Left atrial filling pressure $\left(\mathrm{cm} \mathrm{H}_{2} \mathrm{O}\right)$} \\
\hline & 10 & 15 & 20 & 25 & 30 \\
\hline \multicolumn{6}{|l|}{$\dot{\mathrm{Q}}(\mathrm{ml} / \mathrm{min} / \mathrm{g})$} \\
\hline Control $(n=5)$ & $122.2 \pm 10.9$ & $142.1 \pm 8.2$ & $153.4 \pm 9.6$ & $160.0 \pm 11.7$ & $168.4 \pm 15.5$ \\
\hline Caffeine-fed $(n=6)$ & $135.6 \pm 7.1$ & $153.6 \pm 4.3$ & $160.7 \pm 4.8$ & $168.4 \pm 4.2$ & $178.6 \pm 7.4$ \\
\hline \multicolumn{6}{|l|}{$\mathrm{CF}(\mathrm{ml} / \mathrm{min} / \mathrm{g})$} \\
\hline Control $(n=5)$ & $77.4 \pm 5.5$ & $85.2 \pm 5.1$ & $89.6 \pm 6.1$ & $93.4 \pm 8.4$ & $99.3 \pm 12.6$ \\
\hline Caffeine-fed $(n=6)$ & $87.4 \pm 1.8^{*}$ & $96.9 \pm 2.4^{*}$ & $100.3 \pm 3.2$ & $103.7 \pm 5.0$ & $114.3 \pm 10.7$ \\
\hline \multicolumn{6}{|l|}{ PSP (mm Hg) } \\
\hline Control $(n=5)$ & $106.0 \pm 4.8$ & $116.8 \pm 4.4$ & $119.0 \pm 5.1$ & $124.0 \pm 3.7$ & $125.0 \pm 4.5$ \\
\hline Caffeine-fed $(n=6)$ & $118.7 \pm 4.8^{*}$ & $126.7 \pm 3.1^{*}$ & $128.3 \pm 3.3$ & $133.3 \pm 2.5^{*}$ & $131.7 \pm 2.8$ \\
\hline \multicolumn{6}{|c|}{ Double product $(\dot{\mathrm{Q}} \times \mathrm{PSP})$} \\
\hline Control $(n=5)$ & $13075 \pm 1608$ & $16628 \pm 1407$ & $18398 \pm 1850$ & $19961 \pm 1926$ & $21271 \pm 2613$ \\
\hline Caffeine-fed $(n=6)$ & $16187 \pm 1223$ & $19460 \pm 731^{*}$ & $20601 \pm 715$ & $22453 \pm 700$ & $23540 \pm 1140$ \\
\hline \multicolumn{6}{|c|}{ Oxygen consumption $\left(\mathrm{mM} \mathrm{O}_{2} / \mathrm{h} / \mathrm{g}\right)$} \\
\hline Control $(n=5)$ & $2.58 \pm 0.11$ & $2.71 \pm 0.13$ & $2.86 \pm 0.16$ & $3.06 \pm 0.31$ & $3.27 \pm 0.55$ \\
\hline Caffeine-fed $(n=6)$ & $2.73 \pm 0.21$ & $3.02 \pm 0.21$ & $3.16 \pm 0.18$ & $3.29 \pm 0.22$ & $3.76 \pm 0.38$ \\
\hline
\end{tabular}

* Treatment significantly different from control value, $p<0.05$.

Table 2. Effects of chronic caffeine intake during lactation and postweaning on adipocyte size and number (mean \pm SEM)

\begin{tabular}{ccccc} 
Depot & $\begin{array}{c}\text { Tissue wt } \\
(\mathrm{g})\end{array}$ & $\begin{array}{c}\text { Diameter } \\
(\mu \mathrm{m})\end{array}$ & $\begin{array}{c}\text { TG/cell } \\
(\mu \mathrm{g})\end{array}$ & $\begin{array}{c}\text { No. cells } \\
\left(\times 10^{6}\right)\end{array}$ \\
\hline Epididymal & & & & \\
$\quad$ Control $(n=8)$ & $1.20 \pm 0.12$ & $47.31 \pm 2.18$ & $0.066 \pm 0.009$ & $12.63 \pm 1.37$ \\
$\quad$ Caffeine-fed $(n=10)$ & $1.38 \pm 0.19$ & $52.58 \pm 2.17$ & $0.092 \pm 0.010$ & $9.85 \pm 1.19$ \\
$\quad$ Perirenal & & & & \\
$\quad$ Control $(n=8)$ & $0.87 \pm 1.16$ & $44.52 \pm 3.33$ & $0.067 \pm 0.013$ & $10.11 \pm 1.63$ \\
Caffeine-fed $(n=10)$ & $0.90 \pm 0.13$ & $43.35 \pm 3.34$ & $0.067 \pm 0.011$ & $13.59 \pm 3.94$ \\
\hline
\end{tabular}


cantly higher in the hearts of the caffeine-fed group than in the controls at 10 and $15 \mathrm{~cm} \mathrm{H}_{2} \mathrm{O}$ (Table 1). However, $\mathrm{CF} / \mathrm{Q}$ ratio for the caffeine-fed group $(62-65 \%)$ was not significantly different from control values (58-64\%).

PSP was significantly elevated in hearts from caffeine-fed animals at preloads of 10,15 , and $25 \mathrm{~cm} \mathrm{H}_{2} \mathrm{O}$ when compared to controls (Table 1). Both diastolic pressure and mean pressure increased with left atrial filling pressure, but no differences between groups were noted.

The double product $(\dot{\mathrm{Q}} \times \mathrm{PSP})$ and stroke work $(\dot{\mathrm{Q}} \times \mathrm{PSP} /$

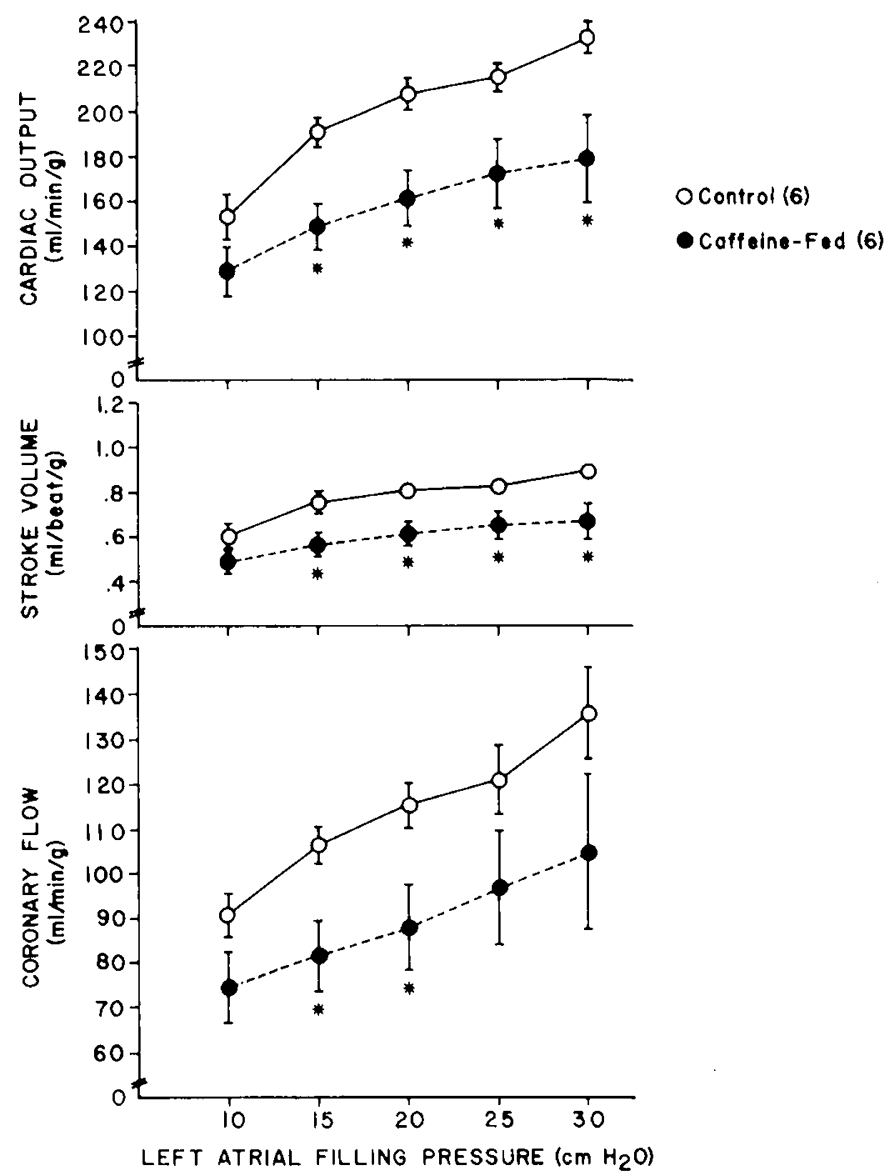

Fig. 1. Changes in $\dot{Q}, S V$, and $C F$ (mean \pm SEM) following chronic caffeine intake during lactation and postweaning in control and caffeinefed rats. Number of hearts per group is given in parentheses. All flows are expressed in terms of dry heart weight. ${ }^{*}$ Treatment is significantly different from control value, $p<0.05$.
HR), which were used to estimate myocardial work, increased with preload in both groups. Although stroke work and double product (Table 1) in caffeine-fed rats were higher than in controls, only $15 \mathrm{~cm} \mathrm{H}_{2} \mathrm{O}$ was significantly different. Similarly, myocardial oxygen consumption increased with preload and myocardial work; however, no significant differences between groups were observed (Table 1). External efficiency remained fairly constant at $6-7 \%$ for both groups of hearts.

Myocardial work correlated well with myocardial oxygen consumption $(r=0.75, p<0.05)$ and coronary flow $(r=0.84, p<$ $0.05)$. However, the slopes and intercepts of the two relationships were not significantly different.

Effect of caffeine intake during lactation and postweaning. The 50-day-old control and caffeine-fed rats exhibited no statistical difference in body, wet heart, and dry heart weights. Adipocyte size or number in both fat depots were not significantly different following continued caffeine ingestion (Table 2).

The cardiac output increased significantly with preload pressure for both groups. However, $\dot{Q}$ was significantly lower for the caffeine-fed group than that of control animals (Fig. 1). Since HR was not statistically different with altered preloads, the experimental group's SV was significantly lower than that of controls at increased preload pressures (Fig. 1). CF was significantly less in the caffeine-fed hearts at intermediate preloads (Fig. 1). Neither the caffeine-fed nor the control hearts displayed statistical differences in CF/Q with increased preload (54-57 and $56-60 \%$, respectively).

Mean aortic pressure was significantly reduced in the hearts from caffeine-fed animals at $15,20,25$, and $30 \mathrm{~cm} \mathrm{H}_{2} \mathrm{O}$ (Table 3). PSP increased with preload pressure; however, PSP was significantly lower in the caffeine-fed group at similar preloads (Fig. 2). The experimental group exhibited a declining diastolic pressure with increased preload pressure that was significant at $25 \mathrm{~cm} \mathrm{H}_{2} \mathrm{O}$.

Work was significantly depressed in the hearts from caffeinefed rats. Double product was significantly less at $15,20,25$, and $30 \mathrm{~cm} \mathrm{H}_{2} \mathrm{O}$ (Fig. 3). Similarly, hearts from caffeine-fed rats exhibited significantly lower stroke work values at these filling pressures (Table 3 ).

Myocardial oxygen consumption for both groups of hearts was not significantly different (Table 3 ). Since hearts from caffeinefed rats produced less work and consumed similar quantities of oxygen as controls, one can conclude that hearts from caffeinefed rats were significantly less efficient at all preloads (Table 3 ).

\section{DISCUSSION}

Effect of caffeine intake during gestation and lactation. Caffeine has been known to easily cross the placenta and accumulate in fetal tissue (29). Similarly, comparable caffeine concentrations

Table 3. Effects of chronic caffeine intake during lactation and postweaning on cardiac performance (mean $\pm S E M, n=6)$

\begin{tabular}{|c|c|c|c|c|c|}
\hline \multirow[b]{2}{*}{ Variable } & \multicolumn{5}{|c|}{ Left atrial filling pressure $\left(\mathrm{cm} \mathrm{H}_{2} \mathrm{O}\right)$} \\
\hline & 10 & 15 & 20 & 25 & 30 \\
\hline \multicolumn{6}{|c|}{ Mean aortic pressure $(\mathrm{mm} \mathrm{Hg})$} \\
\hline Control & $61.2 \pm 2.8$ & $69.7 \pm 3.0$ & $73.3 \pm 3.4$ & $75.5 \pm 3.6$ & $75.5 \pm 4.4$ \\
\hline Caffeine-fed & $57.8 \pm 1.3$ & $62.8 \pm 1.7^{*}$ & $65.2 \pm 1.3^{*}$ & $66.5 \pm 2.2^{*}$ & $65.8 \pm 2.0^{*}$ \\
\hline \multicolumn{6}{|c|}{ Stroke work $(\dot{\mathrm{Q}} \times \mathrm{PSP} / \mathrm{HR})$} \\
\hline Control & $50.2 \pm 6.2$ & $73.6 \pm 5.8$ & $81.5 \pm 4.0$ & $85.0 \pm 4.2$ & $91.9 \pm 4.3$ \\
\hline Caffeine-fed & $37.3 \pm 4.2$ & $47.7 \pm 5.1^{*}$ & $53.8 \pm 6.0^{*}$ & $59.1 \pm 7.6^{*}$ & $59.5 \pm 8.4^{*}$ \\
\hline \multicolumn{6}{|c|}{ Oxygen consumption $\left(\mathrm{mM} \mathrm{O}_{2} / \mathrm{h} / \mathrm{g}\right)$} \\
\hline Control & $2.91 \pm 0.14$ & $3.47 \pm 0.17$ & $3.78 \pm 0.24$ & $3.95 \pm 0.32$ & $4.56 \pm 0.52$ \\
\hline Caffeine-fed & $3.19 \pm 0.24$ & $3.31 \pm 0.22$ & $3.51 \pm 0.27$ & $3.79 \pm 0.41$ & $4.01 \pm 0.58$ \\
\hline \multicolumn{6}{|l|}{ External efficiency $(\%)$} \\
\hline Control & $5.8 \pm 0.6$ & $7.0 \pm 0.7$ & $7.4 \pm 0.7$ & $7.6 \pm 0.7$ & $7.3 \pm 0.8$ \\
\hline Caffeine-fed & $4.2 \pm 0.2^{*}$ & $5.0 \pm 0.2^{*}$ & $5.4 \pm 0.2^{*}$ & $5.5 \pm 0.3^{*}$ & $5.3 \pm 0.3^{*}$ \\
\hline
\end{tabular}

\footnotetext{
* Treatment significantly different from control value, $p<0.05$.
} 


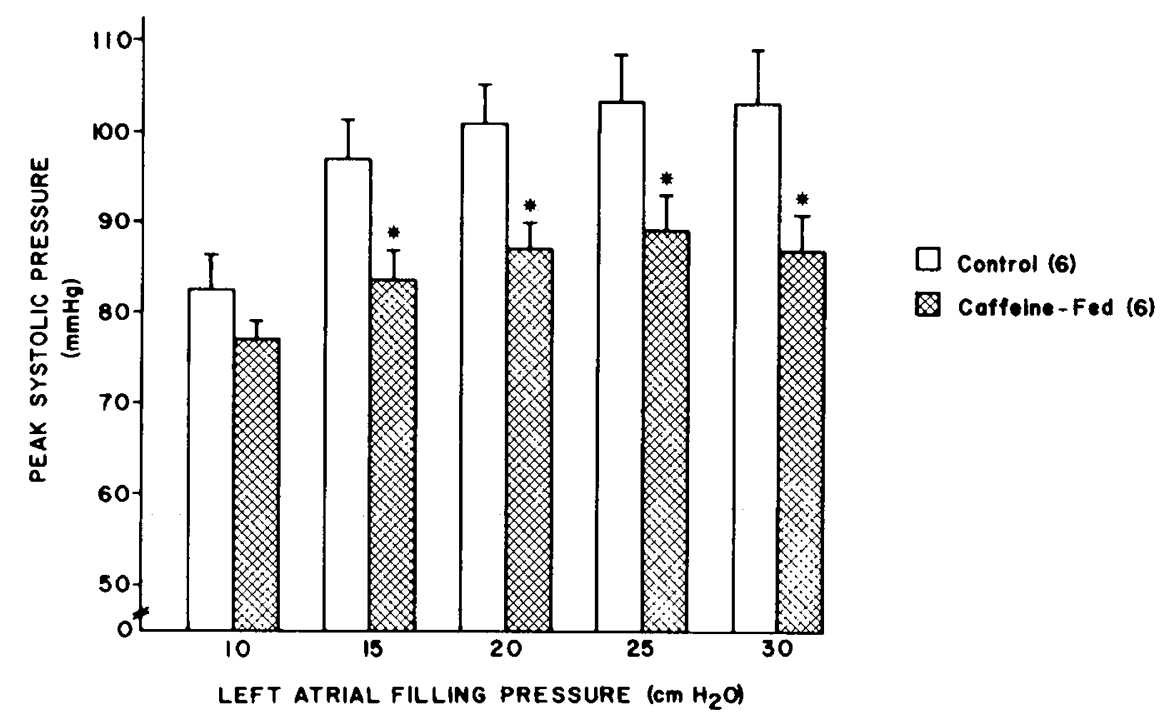

Fig. 2. Changes in PSP (mean \pm SEM) following chronic caffeine ingestion during lactation and postweaning. Number of hearts for each condition is shown in parentheses. ${ }^{*}$ Treatment is significantly different from control value, $p<0.05$.

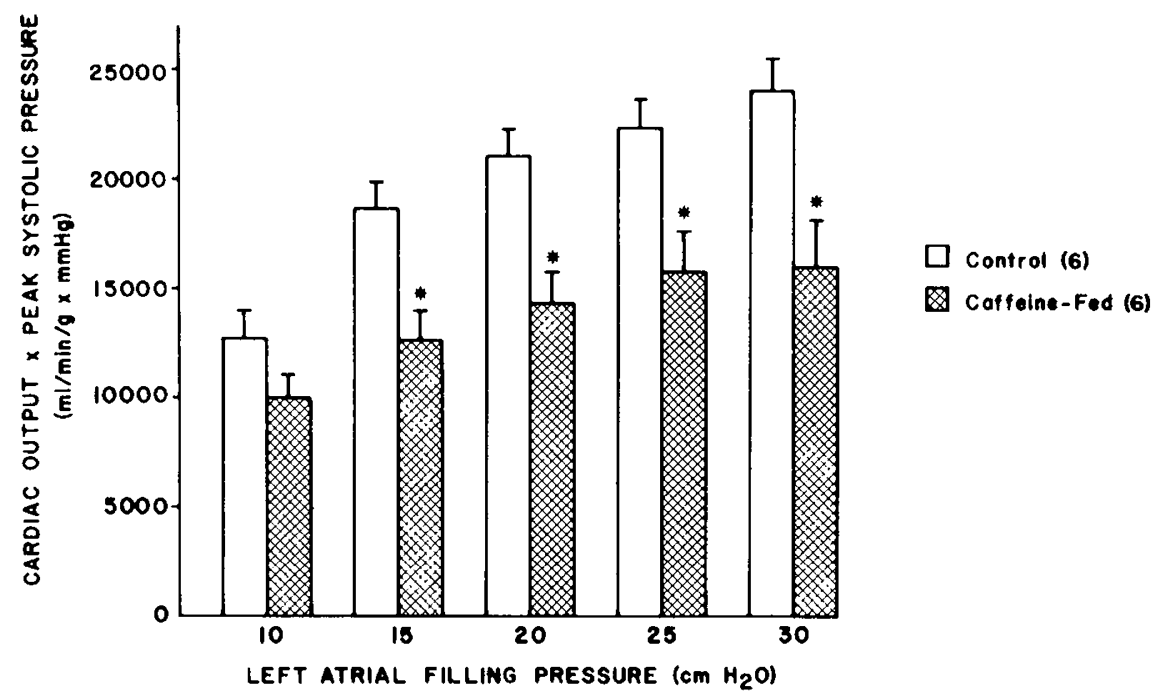

Fig. 3. Changes in estimated myocardial work (mean \pm SEM) following chronic caffeine intake during lactation and postweaning. Number of hearts per group is given in parentheses. ${ }^{*}$ Treatment is significantly different from control value, $p<0.05$.

have been reported in both fetal and maternal plasma (29). Caffeine has also demonstrated an inability to be metabolized in utero (9), possibly resulting from decreased caffeine clearance during early pregnancy $(13,14)$. As a result, offspring that had received caffeine while in utero and during lactation demonstrated modest elevations in pressure development, coronary flow, and myocardial work.

MacCornack (1) denoted that xanthines are potent stimulants of the central nervous system and can exert both positive inotropic and chronotropic effects on the heart. This direct myocardial stimulation is exemplified by an increased HR and decreased blood pressure. Slight coronary vessel dilation has also been reported involving primarily isolated heart preparations (1). However, the present findings differ from the data recorded when offspring were fed during lactation and postweaning in the present study as well as a previous report (30). These data suggest that the period from postweaning to 50 days may be critical for cardiovascular development and function. DNA contents, which is continuously increased during this period of growth (31), may have been disturbed.

Effect of caffeine intake during lactation and postweaning.
Caffeine ingestion during lactation and postweaning resulted in significant changes in cardiac performance when compared to that of controls. $\dot{Q}, S V$, and myocardial work were decreased in hearts of caffeine-treated animals at most preloads. These cardiovascular differences can be partially explained by the caffeine group's reduced ability to develop myocardial pressure. The reduction in cardiac performance might result from an altered length-tension relationship because $\dot{Q}$ is typically increased (32, 33) with a given increase in preload pressure or left atrial volume. In the present study, the caffeine-fed animals produced lower Qs than did the controls at almost all preload pressures. A change in contractility might be the reason for the downward shift in the Starling curve. This would explain the decreased flow and work values in the caffeine-fed animals' hearts. Caffeine intake may possibly affect several variables that can alter contractility: calcium concentrations, heart weight, and myofibrils $(1,34,35)$. In addition, Dews et al. (36) reported that caffeine-fed rats showed reduced cardiac function, possibly by caffeine blocking the adenosine-adenosine receptor interactions. Since no significant change in myocardial oxygen consumption was observed with the corresponding decrease in work output, hearts from 
caffeine-treated rats were significantly less efficient than that of the control counterparts. These entire findings were similar to previously reported work involving rats fed caffeine postbirth (30); however, the depression in the myocardial function was seen in much less time (i.e. 88 versus 50 days postbirth).

Physical characteristics (e.g. dry and wet heart weight) of the hearts from caffeine-fed rats showed no difference from those of controls. By feeding caffeine approximately twice as many days (i.e. 50 to 88 days), we have observed significantly larger hearts than that of the control animals (30). This may indicate that the significant physical enlargement of hearts by chronic caffeine feedings may occur after 50 days postpartum. Conceivably, an insufficient duration of exposure to several factors such as volume- and/or pressure-overload hypertrophy (34), catecholamine release $(37,38)$, renin activity $(2,6)$, and growth hormone (39) may have contributed to the absence of cardiac hypertrophy.

Because of the pronounced effect of caffeine on FFA mobilization (17-20), the epididymal and perirenal depots were examined to determine if this caffeine dosage $(10 \mathrm{mg} / \mathrm{kg} /$ day $)$ would affect adipocyte size or number. Regarding adiposity, our nonsignificant findings were consistent with other studies in which dosages as high as $50 \mathrm{mg} / \mathrm{kg}$ produced no alterations in adipose size or number (21). However, when caffeine was added in higher doses $(65$ and $150 \mathrm{mg} / \mathrm{kg}$ ) to the diet, the adipocyte number and size in the perirenal depot decreased. This finding was observed despite the fact that there were no significant differences in food intake (21). Thus, significantly higher caffeine doses may be necessary to elicit a significant change in adiposity.

In conclusion, chronic caffeine intake during lactation and postweaning produced a significant depression in cardiac function. Conversely, continued caffeine ingestion by dams during gestation and lactation produced modest elevations in cardiac performance. The mechanism(s) of this response remains to be evaluated; but the change in contractility does appear to be related to the duration of caffeine consumption and the animal's stage of growth and development.

Acknowledgments. The authors express appreciation to Dr. Michael G. Levitzky for his invaluable assistance in the preparation of this manuscript and to Dale Shew and Jimmy Morris for their technical assistance.

\section{REFERENCES}

1. MacCornack FA 1977 The effects of coffee drinking on the cardiovascular system: experimental and epidemiological research. Prev Med 6:104-119

2. Rall TW 1980 Central nervous system stimulants: the xanthines. In: Gilman AG, Goodman LS, Gilman A (eds) The Pharmacological Basis of Therapeutics. MacMilian, New York, pp 592-607

3. Grollman A 1930 The action of alcohol, caffeine, and tobacco on the cardiac output (and its related functions) of normal man. J Pharmacol Exp Ther 39:313-329

4. Marcus ML, Skelton CL, Grauer LE, Epstein SE 1972 Effects of theophylline on myocardial mechanics. Am J Physiol 222:1361-1365

5. Izzo JL Jr, Ghosal A, Kwong T, Freeman RB, Jaenike JR 1983 Age and prior caffeine use alter the cardiovascular and adrenomedullary responses to ora caffeine. Am J Cardiol 52:769-773

6. Robertson D, Frolich JC, Carr RK, Watson JT, Hollifield JW, Shand DG, Oates JA 1978 Effects of caffeine on plasma renin activity, catecholamines, and blood pressure. N Engl J Med 298:181-186

7. Curatolo PW, Robertson D 1983 The health consequences of caffeine. Ann Intern Med 98:641-653

8. Robertson D, Wade D, Workman R, Woosley RL, Oates JA 1981 Tolerance to the humoral and hemodynamic effects of caffeine in man. $\mathrm{J}$ Clin Invest 67:1111-1117

9. Weathersbee PS, Lodge JR 1979 Alcohol, caffeine, and nicotine as factors in pregnancy. Postgrad Med 66:165-171

10. Jiritano L, Bortolotti A, Gastari F, Bonati M 1985 Caffeine disposition after oral administration to pregnant rats. Xenobiotica 15:1045-1051

11. Scott WJ Jr 1983 Caffeine-induced limb malformations: Description of malformations and quantitation of placental transfer. Teratology 28:427-435

12. Galli C, Spano PF, Szyszka K 1975 Accumulation of caffeine and its metabolites in rat fetal brain and liver. Pharmacol Res Commun 7:217-221

13. Kling OR, Christensen MD 1979 Caffeine elimination in late pregnancy. Fed Proc 38:266(abstr)

14. Neims AH, Bailey J, Aldridge A 1979 Disposition of caffeine during and after pregnancy. Clin Res 27:236A(abstr)

15. Berlin CM Jr, Denson HM, Daniel CH, Ward RM 1984 Disposition of dietary caffeine in milk, saliva, and plasma of lactating women. Pediatrics 73.59-63

16. Horning MG, Butler CM, Nowlin J, Hill RM 1975 Drug metabolism in the human neonate. Life Sci 16:651-671

17. Acheson KJ, Zahorska-Markiewicz B, Anatharamum K, Jequier E 1980 Caffeine and coffee: their influence on metablic rate and substrate utilization in normal weight and obese individuals. Am J Clin Nutr 33:989-997

18. Bellet S, Kershbaum A, Finck EM 1968 Response of free fatty acids to coffee and caffeine. Metabolism 17:702-707

19. Bellet S, Kershbaum A, Roman L 1968 Effect of cola drinks on serum free fatty acids. Arch Environ Health 17:803-806

20. Jung RT, Shetty PS, James WPT, Barrand MA, Callingham BA 1981 Caffeine its effect on catecholamines and metabolism in lean and obese humans. Clin Sci 60:527-535

21. Bukowiechi LJ, Lupien J, Follea N, Jahjah L 1983 Effects of sucrose, caffeine, and cola beverages on obesity, cold resistance, and adipose tissue cellularity. Am J Physiol 244:R500-R507

22. Quinby GE, Nakamoto $T 1984$ Theophylline effects on cellular response in protein-energy neonatal rat brain. Pediatr Res 18:546-549

23. Fintel MC, Burns AH 1982 A simplified working heart apparatus specialized for use with radioisotopes and oxygen electrodes. Ala J Med Sci 19:129-135

24. Neely JR, Liebermeister H, Battersby EJ, Morgan HE 1967 Effect of pressure development on oxygen consumption by isolated rat heart. Am $\mathrm{J}$ Physiol 212:804-814

25. Hartman AD, Cohen AI, Richane CJ, Hsu T 1971 Lipolytic response and adenyl cyclase activity of rat adipocytes as related to cell size. $\mathrm{J}$ Lipid Res 12:498-505

26. Penpargkul S, Scheuer J 1970 The effect of physical training upon the mechanicai and metabolic performance of the rat heart. J Clin Invest 49:18591868

27. Bruning JL, Kintz BL 1977 Computational Handbook of Statistics. Scott, Foresman, Philadelphia

28. Tallarida RJ, Murray RB 1981 Manual of Pharmacologic Calculations with Computer Programs. Springer-Verlag, New York

29. Martin JC 1982 An overview: maternal nicotine and caffeine consumption and offspring outcome. Neurobehav Toxicol Teratol 4:421-427

30. Temples TE, Geoffray DJ, Nakamoto T, Hartman AD, Miller HI 1985 The effect of caffeine intake during early growth and development on cardiac function. Proc Soc Exp Biol Med 179:388-395

31. Winick M, Noble A 1965 Cellular response in rats during malnutrition at various ages. Dev Biol 12:451-466

32. Goldfarb RD 1982 Cardiac mechanical performance in circulatory shock: a critical review of methods and results. Circ Shock 9:633-653

33. Guyton AC 1976 Textbook of Medical Physiology. Saunders, Philadelphia

34. Grossman W, Carabello BA, Gunther S, Fifer MA 1983 Ventricular wall stress and the development of cardiac hypertrophy and failure. Perspect Cardiovas Res 7:1-18

35. Lin CI, Vassalle M 1983 Role of calcium in the inotropic effects of caffeine in cardiac Purkinje fibers. Int J Cardiol 3:421-434

36. Dews P, Grice HC, Neims A, Wilson J, Wurtman R 1984 Report of the fourth international caffeine workshop, Athens, 1982. Food Chem Toxicol 22:163169

37. Laks MM, Morady F, Swan HJC 1973 Myocardial hypertrophy produced by chronic infusion of subhypertensive doses of norepinephrine in the dog. Chest 64:75-78

38. Ostman I, Sjostund NO, Swedin G 1972 Cardiac norepinephrine turnover and urinary catechol excretion in trained rats during rest and exercise. Acta Physiol Scand 86:299-308

39. Clozel M, Branchaud CL, Tannenbaum GS, Dussault JH, Aranda JV 1983 Effect of caffeine on thyroid and pituitary function in newborn rats. Pediatr Res 17:592-595 